\title{
Daza-Orozco, C. E. (Comp.) (2019). Imaginario social desde las expresiones gráficas en ambientes público-privados del centro de Bogotá. Bogotá: Editorial Universitaria de San Mateo.
}

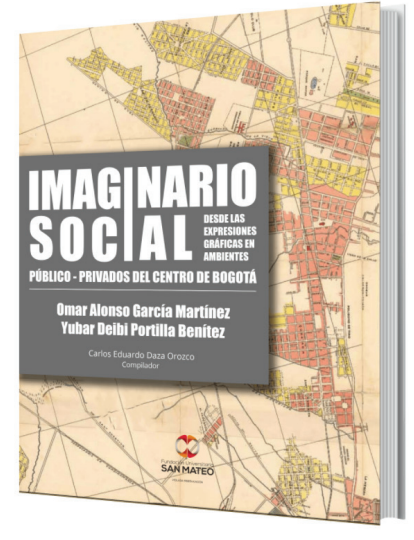

El presente libro fue producto de la labor de dos autores, Omar Alonso García Martínez y Yubar Deibi Portilla Benítez, que buscaron llenar algunos de los vacíos teóricos que han persistido tanto en materia de estudios sobre las experiencias estéticas, como en el abordaje del diseño como objeto de análisis en el estudio de las artes. Sumado a esto, la obra encerró un arduo trabajo de campo que resultó en una amplia compilación de ilustraciones y que, a su vez, fueron producto del uso que ambos autores le dieron a ciertas herramientas metodológicas pertenecientes a otras disciplinas afines. Ello generó la presencia de una idea clave en su trabajo, la de "transdisciplinariedad integral", con la cual incorporaron elementos teóricos más allá de lo técnico, haciendo énfasis también en algunos de los aspectos subjetivos propios de los individuos inmersos dentro las experiencias estéticas; por ello la articulación con la sociología, la antropología y la semiología para el estudio de los imaginarios sociales desde las expresiones gráficas.

El texto propone una trayectoria investigativa en la que, además de elementos propios del estudio de las artes, también se incluyen componentes ligados a los estudios de la memoria y sus representaciones sociales. En palabras de sus mismos autores, este texto es un documento mediado por la historia y las relaciones estéticas que se presentan en el Café Pasaje, La Cervecería Luna Park y el Bar de Doña Ceci, lugares que con el pasar de los años se han vuelto espacios reconocidos por su carácter cultural, social e, incluso, intelectual. De esta forma, establecieron en su trabajo un diálogo entre lo estético, lo simbólico y lo socio-cultural, tomando como objeto de análisis estos tres espacios que, más allá de la pluralidad de imaginarios y representaciones que se generaron a partir de las diferentes experiencias estéticas individuales, con muchos de sus relatos e historias se demostró la esencia vernácula que encierran y representan estos tres sitios para el arraigo social y cultural de Bogotá. 
El libro se encuentra distribuido en cuatro capítulos, tres de los cuales ocuparon cada uno de los espacio público-privados ya mencionados, mientras que el cuarto capítulo se dedicó a ahondar en detalles sobre aspectos conceptuales como la "intimidad" y la existencia de la "soledad" en medio de lo multitudinario. Ambos autores concibieron a la Cervecería Luna Park, Bar de Doña Ceci y El Café Pasaje como espacios distintos, diversos, pero con algunas convergencias sociales y estéticas; la idea de lo público y lo privado, de la unión y la soledad, y de la tristeza y la alegría.

El Bar de Doña Ceci se ubica en el primer capítulo, con una historia cargada de aciertos y desaciertos familiares. García y Portilla parten de la forma en cómo poco a poco, desde la década de los setenta, se fue consolidando este espacio sociológico de carácter público-privado. Estudiantes, artistas y profesionales, utilizaron este sitio como trampolín para deslizarse entre lo rutinario y el ocio productivo, muchos de ellos hallando allí inspiración para sus expresiones artísticas e intelectuales, en medio de tertulias y bebidas embriagantes. Similarmente ocurrió con la Cervecería Luna Park, lugar estudiado en el segundo capítulo. Este sitio, además de servir como lugar de peregrinaje citadino desde mediados de los sesenta, y de estar rodeado de un cordón de universidades públicas y privadas por todo su perímetro, también ha sido testigo de muchas anécdotas abrazadas por la pasión deportiva, lo que a fin de cuentas generó una adecuada asimilación del tema desde un enfoque antropológico. Y por último, El Café Pasaje, el más longevo de los tres espacios seleccionados para la investigación. Este lugar fue impulsado con la astucia de un ingeniero de profesión que vio en el mercado cafetero colombiano un desafío para sí mismo y, a raíz de los años que la respaldan, ha sido espectador de primera plana frente a muchos acontecimientos históricos que han acaecido en las cercanías del centro histórico de Bogotá, convirtiéndolo en uno de los espacios sociales más insignes de la capital de la República y en el que, de la misma forma que en la Cervecería Luna Park, también germinó la semilla del deporte.

Para terminar, en lo personal quiero resaltar que este trabajo puede encajar, además, dentro de los estudios encargados de abordar la conformación y la resonancia de los espacios de sociabilidad de carácter cultural e intelectual, al estilo investigativo del historiador francés Maurice Agulhon. Al igual que con las conclusiones pioneras construidas por este historiador, en el trabajo emprendido por García y Portilla se evidencia entonces una estrecha correlación, de naturale- 
entre el papel del individuo portador de la experiencia estética y el espacio físico y gráfico que lo rodea.

\section{KEVIN RAMÍREZ COCHEZ}

Universidad de Cartagena

kramirezc@unicartagena.edu.co 